\title{
The Buildings Explosion Venting Research For The Gas Resource Utilization
}

\author{
Tianhui Zhao ${ }^{1, a^{*}}$,Ruliang Zheng ${ }^{1, b}$ \\ ${ }^{1}$ State Key Laboratory of Disaster Prevention and Mitigation of Explosive and Impact,PLA \\ University of Science and Technology,Nanjing 210007,China \\ aZTH0210@163.com, bzhengruliang1@163.com
}

Keywords: Gas explosion, Deflagration venting, Light friable system,Vent area, Detection method Abstract. For the advantages such as clean and environmental,the gas has been frequently used in human production and living.However,the gas explosion also becomes the major threaten for the production safety,the casualties caused by which is mainly due to the buildings collapse.This paper studies the deflagration venting of the buildings.First,by combining the research home and abroad,we analyze the impacts of vent area on the explosion pressure. We Compare different countries' specification of explosion venting area, and obtain the general conclusions about discharge area.Then,by taking domestic present status into account,we introduce the inertial venting system and light friable system of the buildings, and analyze the current problems existing in the venting system. Finally,we put forward the future development direction for the venting system of buildings.

\section{Introduction}

Gas has become commonly used energy in people's production and life.Gas, for example, are widely used as city gas and industrial fuel, there is gas in every house and plant .But at the same time, because the gas itself is flammable and explosive,gas explosion is a common "killer" in life and production.Gas produces high pressure within the building, buildings may be collapsed at a certain range from the explosion center. It threats the production safety and personnel security a lot . 2010 Nanjing plastic factory exploded because of gas leak , and many people were killed or injured in the serious safety accidents. One of the probably most known examples of explosion in household was Ronan Point explosion at the end of the 60s in England[1]. This accident led to changes in construction regulations and also to changes in construction of concrete panel buildings. Another study dealing with venting of explosion in households arising from this accident was published by Dragosavic (1973) [2] and recommnded in EN 1991-1-7[3][4].

Deflagration venting is a protection way to limit the explosion pressure.It through open upfront designed pressure relief hole, releasing smoldering mixture and combustion products, prevent the intensity of pressure from rising more than designed value in order to protect the container or structure. Therefore, explosion venting system is particularly important in explosion accident prone buildings.

\section{Influence of explosion vent area on pressure}

Because of the complexity of combustible gas explosion, the current researches on gas explosion focused on explosion inside container and gas explosion pressure measurements within the scope of in a small space.Venting process in large buildings is difficult to achieve in the actual experiment,so fitting process of a gas explosion inside buildings, mainly through data obtained in gas explosion in vessel[4-6],purely empirical formulas and numerical simulation to achieve. The key to vent is unloading the pressure through vent port,so many studies have focused on the relationship between the vent area and the venting pressure. 


\section{Nomenclature:}
$A_{v} \quad$ vent area $\left(\mathrm{m}^{2}\right)$
$V \quad$ vessel volume $\left(m^{3}\right)$
$K \quad$ Ratio of Vent area and volume $\left(\mathrm{m}^{2} / \mathrm{m}^{3}\right)$
$P \quad$ Pressure of the outer wall $\left(\mathrm{kg} / \mathrm{cm}^{2}\right)$
$A_{s} \quad$ vessel surface $\left(\mathrm{m}^{2}\right)$
e Euler number
$p_{\text {red }}$ maximum reduced pressure in vessel during explosion $(\mathrm{Pa})$

The last century, Chinese Ministry of Industry Institute simulate window venting experiments in industrial plant using a one cubic rectangular meter of metal box to obtain the relationship between the window area and the explosion pressure relief inside the box[5].Fig.1 is the relationship between window area ratio $\mathrm{K}$ and the explosion pressure $\mathrm{P}$ with $7.7 \%$ acetylene-air mixtures in the rectangular vessels.
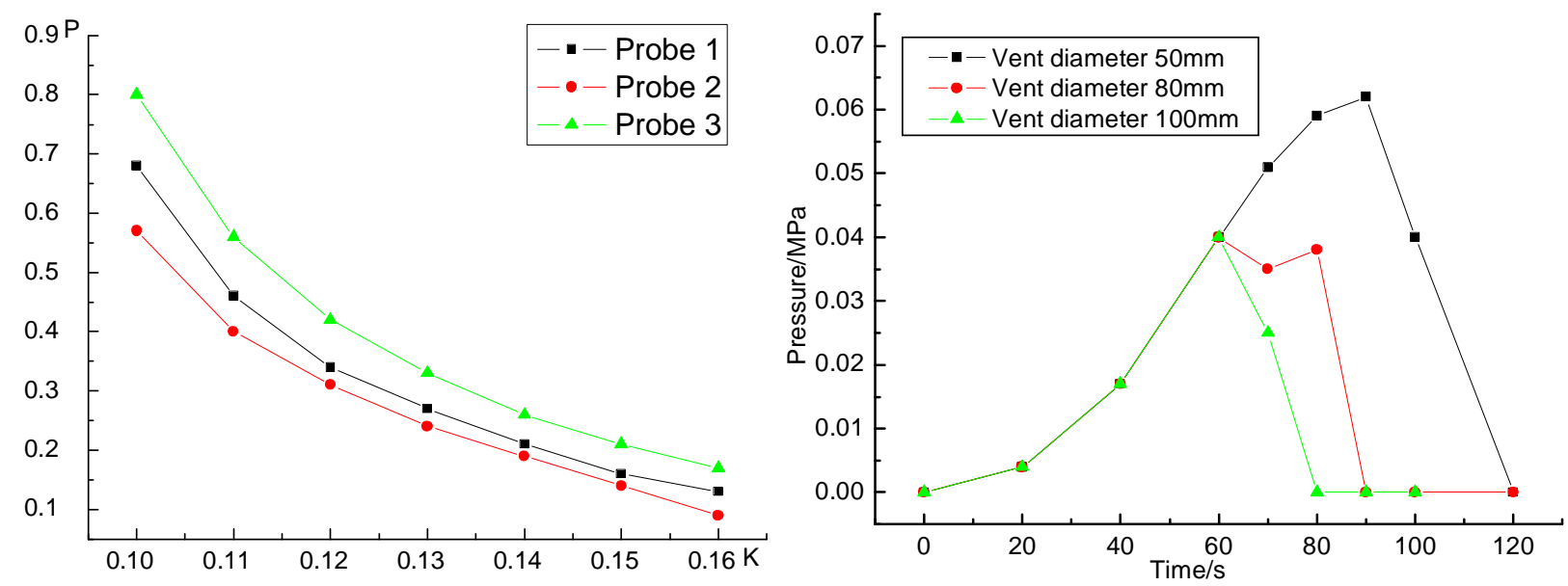

Fig.1.The relationship between Vent area and Pressure Fig.2.The results of numerical simulation ( $7.7 \%$ acetylene-air mixtures)

Results indicate the greater the relief area, venting the better.And similar experiments in Europe and other countries have also got the same results.National Fire Protection Association Standard NFPA 68 provides container in an aspect ratio of not more than 3 , according to the experimental data fitting formula[6]

$$
p_{\text {red }}=0.1\left(C A_{S}\right)^{2} / A_{V}^{2}
$$

The experimental spectra of Simpson and Bartknecht fitting to the formula

$$
p_{\text {red }}=0.1\left(\frac{A_{V}}{a V^{b} e^{10 c p}{ }_{\text {stat }}}\right)^{\frac{1}{d}}
$$

also be included in NFPA68.Fitting formulas suggested, with the increase of pressure relief area, the pressure decreases in venting process. The specification about relief area of explosion hazard plant are different in different countries. Table 1 is the ratio of industrial plants volume and relief area of America.And Table 2 is the ratio of industrial plants volume and relief area of Japan[5].

Table 1 Ratio of Vent area and volume(America)

\begin{tabular}{|l|l|}
\hline Plant Level(class of inflammable gase) & Ratio of Vent area and volume $=\mathrm{K}\left(\mathrm{m}^{2} / \mathrm{m}^{3}\right)$ \\
\hline Weak(dust particle) & 0.0332 \\
\hline Moderate(braize, zinc dust, synthetic resin) & 0.0650 \\
\hline Strong(steam,aluminitepowder) & 0.220 \\
\hline Superfine(acetone,acetylene,hydrogen) & Biggest possible \\
\hline
\end{tabular}


Table 2 Ratio of Vent area and volume(Japan)

\begin{tabular}{|l|l|}
\hline Plant Level(class of inflammable gases) & Ratio of Vent area and volume $=\mathrm{K}\left(\mathrm{m}^{2} / \mathrm{m}^{3}\right)$ \\
\hline Weak(grain,paper,copper powder) & 0.033 \\
\hline Moderate(saudust, coal, urea,Tin powder) & 0.066 \\
\hline $\begin{array}{l}\text { Strong(Starch filled with gas, cellulose acetate } \\
\text { fiber, furfural phenol resin) }\end{array}$ & 0.200 \\
\hline Superfine(acetone,acetylene,gasoline,hydrogen) & Bigger than 0.200 \\
\hline
\end{tabular}

Factory in China about the risk of explosion relief area ratio from 0.05 to 0.1 or so.For particularly large volume of industrial plants, if the space is too big to reach the explosion limit and it's difficult make $\mathrm{K}$ be 0.05 , let $\mathrm{K}$ not less than 0.03 . Thanks to the development of computer technology in recent years,numerical simulation of gas explosion become more mature.DongBingyan uses classical fluid dynamics software FLUENT to simulate the venting process of mixture of methane and air with different vent port diameter[8]. The results shown in Fig 2,it also verified the relationship between vent area and the vent pressure.Naamans from Cambridge University use non-structural software McNEWT CFD did two-dimensiona numerical simulation of IIbrahim's experiments[9]. He got flame speed, pressure characteristics when through obstacles burning transfer from the layer becomes turbulent,provide the study of venting with data and theoretical support.Currently scholars generally use software such as AUTOReaGas ,BI AST ,FLUENT, PHOENICS ,EXSIM to simulate the process of explosion of flammable gas and venting process

\section{Building vent system}

Venting system of the building including vent windows, vent walls and vent roof .In the case of ensuring adequate venting area, venting components have to meet the requirements of light,fire protection, thermal insulation and soundproofing . Chinese construction on the building venting system generally in accordance with national building standards Atlas 14J938[10]. Vent windows, vent walls and vent roof generally divided into two types, one is light pressure relief system based on vent bolt,pressure plate and the keel is bolted, when the pressure reaches a predetermined value, venting bolt will automatically open,it's work Principle shown in Fig 3.Commonly used pressure plate,material selection is slightly different because of the requirements of translucent and insulation. At the same time, in order to prevent color steel sandwich flying there is traction control noose between the color plate and wall beams, as shown in Fig 3.This method is safe and reliable, venting pressure can be customized, the system can be reused after venting, while venting system reliability, thermal, acoustic insulation, and other functions without disturbing each other. Currently the majority of European countries adopt the bolt based venting system.

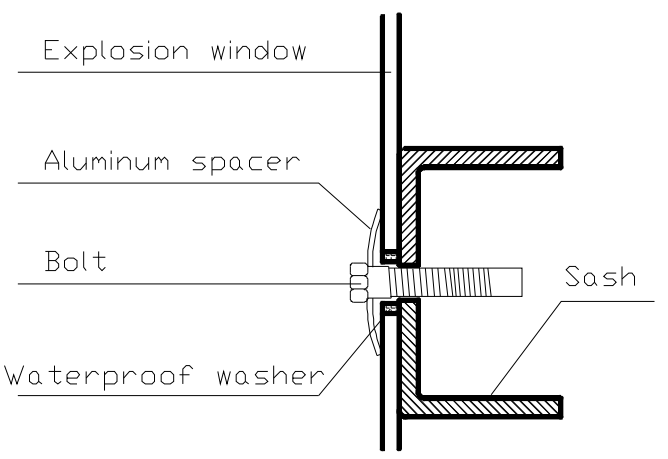

(a)Normal state After installation

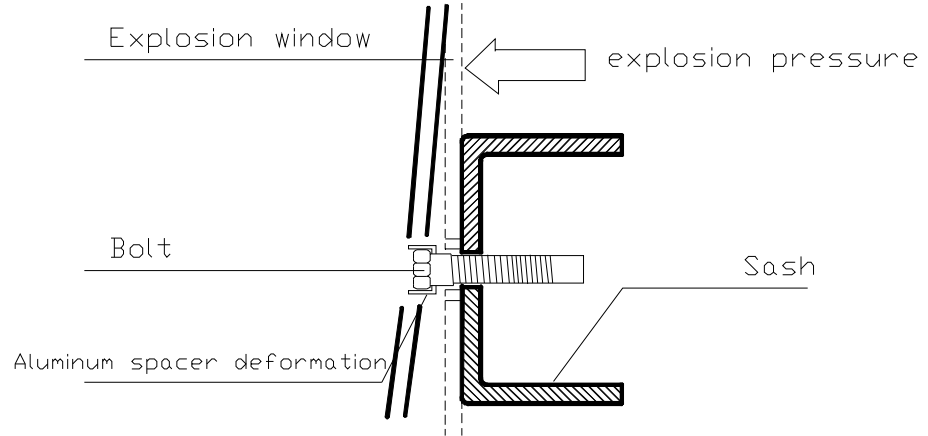

(b)State of pressure release

Fig.3.working principle of Explosion bolt

The second is a light friable system based on a lightweight frangible plate,the vent wall break when the pressure of the vent doors and windows greater than the light intensity of a brittle material.Only when pressure in the chamber is greater than the sum of weight and strength of the wall,will the vent 
roof open, so must use light material. Lightweight frangible plate not only has the relief effect, but also broken into smaller pieces, reducing the impact on the exterior of the building, as shown in Fig 4 . According to vent wall, for example, there is fiber cement wall, expanded light wall, foam concrete composite Wall,specific production methods and requirements of each wall are clearly defined in the 14J938. Overall, light friable type of venting system can basically meet the general requirements of venting, the cost is relatively low, but because of its particularity explosion vent principle, it is difficult to meet the vent pressure while meeting a relatively high noise insulation requirements. And it can not be reused, is gradually being eliminated by the market.

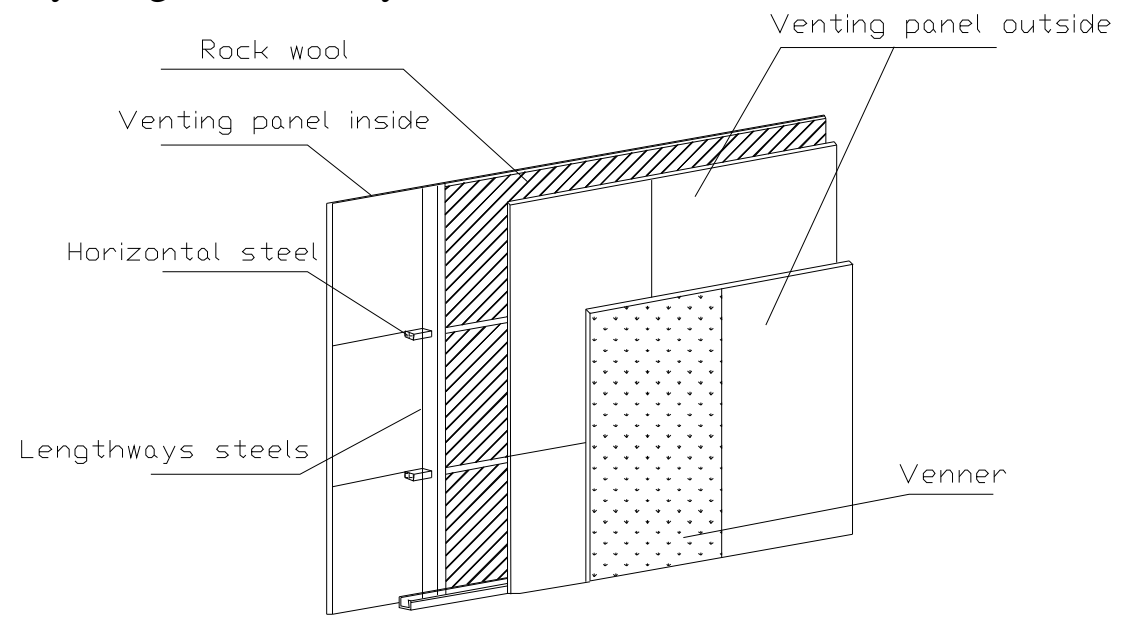

Fig.4 Fiber reinforced cement boards[10]

Although China and many other countries has a relatively clear regulatory requirements in the design and construction of building venting systems, due to the complexity of the combustible gas explosion, general scientific experiments is difficult to fully replicate a gas explosion inside the building conditions, now the market resulting in the vent walls and other products lack authoritative testing methods, but also caused difficulties on the further development of venting system.

\section{Conclusion}

Because of its special superiority, gas energy will play a more and more important role in the human production and living.Presently the understanding of the mechanism of combustion explosion is not unity, and after mouth opening container or building flow field changes very suddenly, further increased the complexity of the theoretical analysis.Experimental study and numerical simulation become the current main approaches to the study of the explosion. After long time of development the study of building explosion has made some achievements, but at home and abroad the research still existing the following deficiencies:(1)Lack of theoretical support, and most of specifications reference to the result of the experiment, so,the suitable scope is limited, predicted results different a lot with the actual result .(2)For numerical simulation can only roughly display the flow field of the explosion process of change trend, the verification result such as the explosion pressure and explosion venting area are difficult to guide the study of explosion venting system.(3)Currently venting experiment are mostly concentrated in the container simulations, it is relatively less experiment concentrated in venting the building.But the results inside the container do not necessarily apply to the situation in buildings.(4)Lack of authoritative and practical detection methods to the existing venting products. Future need for in-depth study of the theoretical analysis of venting, and try to find simplified experimental methods to simulate the gas explosion. And develop venting detection methods,indicate the direction of venting research and engineering design from multiple perspectives.

\section{References}

[1]Griffiths, H., Pugsley, A. G., \& Saunders, O. (1968). Report of the inquiry into the collapse of flats at Ronan Point, Canning Town. London: Her Majesty's Stationery Office. 
[2] Dragosavic, M. (1973). Structural measures against natural-gas explosions in highrise blocks of flats. Heron.

[3] EN 1991-1-7. Eurocode 1: actions on structures e part 1-7: general actions -accidental actions.

[4]J.Sustek,B.Janovsky: Comparison of empirical and semi-empirical equations for vented gas explosion with experimental data(2013).

[5]Qingqiao Zeng. Explosion-proof design of construction,In Chinese(1986), P48-P53.

[6] NFPA 68. (2013). Guide for venting of deflagrations (2013 ed.). Quincy, MA, USA:National Fire Protection Association.

[7] Simpson, L. L. (1986). Equations for the VDI and Bartknecht nomograms. Plant Operations Progress, 5(1), 49-51.

[8]Bingyan Dong,Xu Peng. Numerical simulation of cylindrical vessel venting. Chinese Safety Science Journal [ J] . Chinese journal of sciencesafety,2011,21(11):1-5.

[9]Jie Lu . Features and Safety Control of multivariate mixed gas explosion [D] . Beijing Science Technology University , 2003.

[10]Chinese construction on the building venting system generally in accordance with national building standards Atlas 14J938,2014. 